\title{
Diskussion
}

\author{
Albrecht Dümling (Berlin)
}

\section{Stellungnahme zum Beitrag „Friedrich Blumes Entnazifizierungsver- fahren" von Michael Custodis (in: Die Musikforschung 2012, Heft 1)}

Anhand bisher unbekannter Quellen beschreibt der Autor die „verschiedenen Karriereschritte und Gratifikationen“ Friedrich Blumes als zielbewusstes Streben nach „Wirkungsmacht“ und Geld. Obwohl die näheren Umstände seiner Verbeamtung 1938 in Kiel „bislang nicht bekannt" sind, wird suggeriert, Blumes Karriere verdanke sich wesentlich seinem Kontakt zu Ministerialrat Herman-Walther Frey. Custodis verwendet mehr als ein Drittel seines Beitrags, um diese „Forschungslücke“ zu schließen. Über Blume erfährt man daraus kaum mehr, als dass er mit dem einflussreichen NSDAP- und SA-Mitglied Frey in Verbindung stand und dieser ihn positiv beurteilte. Die Frage, ob sich sein Aufstieg möglicherweise nicht in erster Linie einem solchen Kontakt, sondern seiner wissenschaftlichen Qualifikation verdankt, wird nicht gestellt.

Stattdessen vertritt der Autor die Meinung, Friedrich Blume habe sich mit Rücksicht auf seine Karriere 1938 in einer "gezielten Strategie“ dem Thema „Musik und Rasse“ zugewandt, dies ausgerechnet in einem Moment, als sich der institutionelle und öffentliche NS-Terror gegen Juden und ihre Einrichtungen in Deutschland verschärfte. Indem Custodis beides in einen unmittelbaren Zusammenhang stellt (S. 18), wirft er Blume vor, mit seinem Düsseldorfer Vortrag und den nachfolgenden Veröffentlichungen die Judenverfolgungen unterstützt zu haben. Als „Beleg“ weist er (Fußnote 90) auf Pamela Potter hin, die Blumes Beschäftigung mit dieser Thematik als Mischung aus Eitelkeit und kalkuliertem Profit bewertet habe. (Übergangen wird dabei Potters inhaltliche Auseinandersetzung mit Blume.)

Als gravierenderen „Beleg“ zitiert der Autor eine problematische Passage aus Blumes Düsseldorfer Vortrag „Musik und Rasse“, um diesen dann insgesamt mit einer „routinierten Propagandaschrift" vergleichen zu können. Diese selektive Zitierweise ist höchst irreführend. Denn mit dem zitierten Rückgriff auf den Nazi-Jargon leitete Blume seine kritische Argumentation ein, wonach alle uns bekannte Musik nicht rassenrein, sondern rassisch gemischt sei. Nach dieser systemkonformen, aber nicht notwendig rassistischen Einleitung konnte er dann ausführlich und keineswegs „mehrdeutig“ auf fremde Einflüsse auf die deutsche Musik eingehen, welche über die Jahrhunderte nicht schädlich, sondern befruchtend gewirkt hätten. Damit widersetzte er sich den damaligen Idealen von Rassenreinheit und Germanentum. Ebenfalls gegen Nazi-Vorstellungen gerichtet waren Blumes Ausführungen über die Vieldeutigkeit der Musik, die sich raschen Zuordnungen entziehe, sowie über ihre Übertragbarkeit von einer Rasse zu einer anderen. Mit solchen Argumenten belegte er die methodologische Problematik jeder musikalischen Rassenforschung, von der man schnelle Ergebnisse nicht erwarten dürfe. Mit dieser Feststellung wollte Blume wohl nicht - wie Custodis insinuiert - „vor allem strategisch“ seine eigene Verbeamtung fördern (S. 3), sondern vielmehr übereilte Urteile von sogenannten Rassenforschern wie Richard Eichenauer, Gotthold Frotscher oder Hans Severus Ziegler, dem Urheber der PropagandaAusstellung „Entartete Musik“, infrage stellen. 
1988 war deshalb in der kommentierten Rekonstruktion der Ausstellung „Entartete Musik“ Blumes Düsseldorfer Vortrag als „Sand ins Getriebe“ bewertet worden. Auf den Ausstellungstafeln „Musik und Rasse“ konnte man lesen, Blume habe „mit List und wissenschaftlicher Sorgfalt den übereifrigen Säuberern vom Schlag eines Ziegler“ die Arbeit erschwert. Um den Ausstellungsbesuchern eine Überprüfung zu ermöglichen, war die Druckfassung seines Vortrags im Katalog vollständig faksimiliert worden. Bei genauer Lektüre konnte man feststellen, dass es sich dabei keineswegs um eine Propagandaschrift handelt, sondern um den schwierigen Balanceakt, innerhalb einer Diktatur zum Nachdenken anzuregen. 1938 war der Vortrag durchaus in diesem Sinne verstanden worden (vgl. Düsseldorfer Nachrichten, 20. Mai 1938, und Frankfurter Zeitung, 31.05.1938). In ihrem Beitrag „Wissenschaftler im Zwiespalt" hatte Pamela Potter im Ausstellungskatalog geschrieben, Blumes sorgfältig formulierter Text widme sich der methodologischen Problematik „sehr vorsichtig“. Noch bemerkenswerter ist, dass Blume das Judentum, zu dessen Abwehr die nationalsozialistische „Rassenforschung“ doch in erster Linie entstand, in diesem Referat nicht ein einziges Mal erwähnte. Er behandelte darin viele Probleme, auch die Bewertung der Gregorianik, nicht aber das Judentum.

Die von Custodis zitierte Erklärung Friedrich Blumes vom 7. Oktober 1947, wonach er im Mai 1938 in Düsseldorf ausgeführt habe, dass es „keine wissenschaftlich stichhaltige Begründung für die Verquickung der Musik mit rassischen Fragen " gebe, ist demnach keine bloße Schutzbehauptung. Noch 1944 wiederholte er in der zweiten Auflage seines Buches „Das Rasseproblem in der Musik“ seine Feststellung von 1939, „daß wir von dem Zusammenhange zwischen Musik und Rasse wissenschaftlich vorläufig keinerlei gesicherte Kenntnis haben“. Auch mit den Urhebern der Propaganda-Ausstellung „Entartete Musik“ hat sich Blume kritisch auseinandergesetzt. Durch ein verheerendes Gutachten über Otto zur Nedden, den engsten Mitarbeiter Zieglers, verhinderte er 1940 dessen musikwissenschaftliche Habilitation. Neddens Begleitvortrag zur Düsseldorfer Ausstellung bezeichnete Blume in diesem Gutachten mit wünschenswerter Deutlichkeit als „Pamphlet, zusammengesetzt aus billigen Schlagworten, angemassten Urteilen und oberflächlichen Gemeinplätzen“. Nedden musste u. a. wegen dieser Intervention zur Theaterwissenschaft ausweichen (vgl. Katalog „Das verdächtige Saxophon“, S. 199).

Indem Custodis Friedrich Blumes Düsseldorfer Vortrag „Musik und Rasse. Grundfragen einer musikalischen Rassenforschung" mit einer Propagandaschrift verglich und in den Zusammenhang der Judenverfolgungen stellte, verkehrte er dessen Absichten ins Gegenteil. Die Information, dass der Vorsitzende der Entnazifizierungskommission ein Nazi war, dient ihm vor allem dazu, die Bewertung Blumes durch diese Kommission als fragwürdig erscheinen zu lassen. Unterstellt wird damit, wie schon seine Karriere sei auch seine Entnazifizierung in erster Linie dubiosen Seilschaften zu verdanken. In diesem Sinne verstand den Aufsatz der Journalist Helmut Mauró, der ihn in der Süddeutschen Zeitung vom 9. Mai 2012 (S. 11) unter der Überschrift „Charakterlich geprüft und doch ein Hetzer. I Kampfbündler Friedrich Blume: Es gibt jetzt handfeste Beweise für die Nazi-Vergangenheit des einflussreichsten deutschen Musikwissenschaftlers“ zusammenfasste. Custodis wird dort so zitiert: „Blume wollte in seinem Fach an die Spitze, er war nicht nur Mitläufer, sondern ideologischer Hetzer. "Was ist das aber für ein Hetzer, der die Parteimitgliedschaft ebenso ablehnt wie die Grußformel „Heil Hitler“, der zu methodologischer Skepsis auffordert, der die Urheber einer Propagandaausstellung bekämpft und sich weigert, den ,jüdischen Einfluss" als Problem zu sehen? 